\title{
Thermosensitive liposomal drug delivery systems: state of the art review
}

This article was published in the following Dove Press journal:

International Journal of Nanomedicine

16 September 2014

Number of times this article has been viewed

\author{
Barbara Kneidl ${ }^{1,2}$ \\ Michael Peller ${ }^{3}$ \\ Gerhard Winter ${ }^{2}$ \\ Lars H Lindner' \\ Martin Hossann' \\ 'Department of Internal Medicine \\ III, University Hospital Munich, \\ 2Department of Pharmacy, \\ Pharmaceutical Technology and \\ Biopharmaceutics, ${ }^{3}$ Institute for \\ Clinical Radiology, University \\ Hospital Munich, Ludwig-Maximilians \\ University, Munich, Germany
}

\begin{abstract}
Thermosensitive liposomes are a promising tool for external targeting of drugs to solid tumors when used in combination with local hyperthermia or high intensity focused ultrasound. In vivo results have demonstrated strong evidence that external targeting is superior over passive targeting achieved by highly stable long-circulating drug formulations like PEGylated liposomal doxorubicin. Up to March 2014, the Web of Science listed 371 original papers in this field, with 45 in 2013 alone. Several formulations have been developed since 1978, with lysolipid-containing, low temperature-sensitive liposomes currently under clinical investigation. This review summarizes the historical development and effects of particular phospholipids and surfactants on the biophysical properties and in vivo efficacy of thermosensitive liposome formulations. Further, treatment strategies for solid tumors are discussed. Here we focus on temperature-triggered intravascular and interstitial drug release. Drug delivery guided by magnetic resonance imaging further adds the possibility of performing online monitoring of a heating focus to calculate locally released drug concentrations and to externally control drug release by steering the heating volume and power. The combination of external targeting with thermosensitive liposomes and magnetic resonance-guided drug delivery will be the unique characteristic of this nanotechnology approach in medicine.
\end{abstract}

Keywords: thermosensitive liposomes, phosphatidyloligoglycerol, hyperthermia, high intensity focused ultrasound, drug delivery, drug targeting

\section{Thermosensitive liposomes and their historical development}

Liposomes are spherical vesicles formed by a membrane bilayer usually composed by phospholipids (Figure 1). The membrane encloses an aqueous core that can be used to encapsulate hydrophilic drugs, whereas lipophilic drugs can be incorporated into the membrane. Several methods are available for preparation of liposomal formulations, ranging from laboratory scale to Good Manufacturing Practice production for clinical batches. ${ }^{1}$ Loading of drugs can be achieved by active (Figure 2A) or passive (Figure 2B) loading methods. Stable encapsulation of a drug inside a liposomal formulation increases its half-life in the circulation after intravenous administration by avoiding rapid metabolism. Moreover, unwanted distribution in different compartments of the body is avoided, so the risk of drug-related side effects is reduced. The versatility of liposomal drug delivery systems reflects the fact that their biophysical characteristics, eg, vesicle size, lamellarity, surface charge, membrane fluidity, and surface, can be modified by the lipid composition and/or preparation method used. Since naturally occurring molecules like (phospho)lipids and cholesterol are used as the main components, liposomes are in general classified as biocompatible.

In 1965, Bangham et al described the spontaneous formation of liquid crystals after dispersing lecithin in aqueous medium. ${ }^{2}$ Although the in vivo results were initially promising, ${ }^{3,4}$ the development of liposomes nearly came to an end in 1982
Martin Hossann

Medizinische Klinik und Poliklinik III,

Klinikum der Universität München,

Marchioninistrasse I5, D-81377 München,

Tel +49894400 73I53

Fax +4989440078694

Email martin.hossann@med.

uni-muenchen.de
International Journal of Nanomedicine 20I4:9 4387-4398

4387

Dovepress

http://dx.doi.org// $0.2147 / 1 J N . S 49297$ (c) (i) (5) 2014 Kneidl et al. This work is published by Dove Medical Press Limited, and licensed under Creative Commons Attribution - Non Commercial (unported, v3.0) License. The full terms of the License are available at http://creativecommons.org/licenses/by-nc/3.0/. Non-commercial uses of the work are permitted without any further permission from Dove Medical Press Limited, provided the work is properly attributed. Permissions beyond the scope of the License are administered by Dove Medical Press Limited. Intormation on
how to request permission may be found at: http://www.dovepress.com/permissions.php 

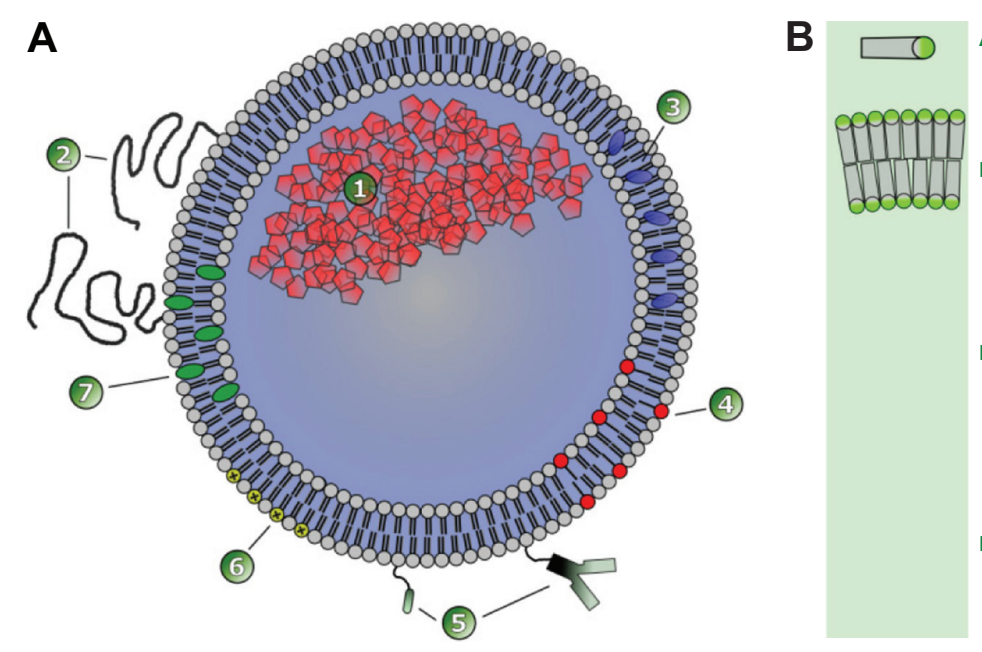

Amphiphilic molecules forming lamellar structures

Figure I Structure of liposomes and examples for membrane components.

Notes: (A) Schematic representation of a liposome. The vesicle is formed by a membrane bilayer of phospholipids enclosing an aqueous internal core that can be loaded with hydrophilic molecules (I). The vesicle surface is often shielded by a polymer coating, eg, polyethylene glycol (2). Lipophilic molecules can be incorporated into the membrane bilayer (3). To destabilize the membrane for facilitating drug release, surfactants (eg, lysolipids) are incorporated into the membrane (4). Surface modification with antibodies, antibody fragments, or ligands yields formulations for active targeting towards the desired epitope (5). Incorporation of cationic lipids like DPTAP yields vesicles for endosomal targeting (6). Cholesterol is incorporated to stabilize the formulations (7). (B) Examples of amphiphilic molecules forming lamellar structures.

Abbreviations: DPPC, I,2-dipalmitoyl-sn-glycero-3-phosphocholine; DPPG , 1,2-dipalmitoyl-sn-glycero-3-phosphodiglycerol; DPTAP, I,2-dipalmitoyl-3-trimethylammonium-propane.

when doubts arose about their ability to target drugs to cells in tissues beyond the endothelial barrier. ${ }^{5}$ Nevertheless, in the years since, due to discovery of steric stabilization of vesicles with polyethylene glycol (PEG), ${ }^{6,7}$ liposomes have been successfully developed as a carrier for drugs, and several liposomal drugs (eg, Doxil ${ }^{\circledR} /$ Caelyx $^{\circledR}$ [Johnson \& Johnson, New Brunswick, NJ, USA] and Ambisome ${ }^{\circledR}$ [Gilead, Foster City, CA, USA]) have been approved and entered the clinic. ${ }^{8}$

In 1978, Yatvin et al described the first temperaturesensitive formulation (thermosensitive liposome, TSL) that was able to release a hydrophilic drug when the temperature was increased a few degrees above physiological temperature. ${ }^{9}$
The original formulation based on 1,2-dipalmitoyl-sn-glycero-3-phosphocholine (DPPC) and 1,2-distearoyl-sn-glycero3-phosphocholine (DSPC) 3:1 ( $\mathrm{mol} / \mathrm{mol}$ ) has been modified frequently during recent decades to overcome several limitations. At the beginning of the 21 st century, the first TSL formulation developed by Needham et al entered human clinical trials. ${ }^{10}$ This was a breakthrough in the field, visible by approximately 300 citations of the original paper ${ }^{11}$ since its publication. Heat-triggered drug release from liposomes can also be achieved by adding thermosensitive polymers to the formulation. ${ }^{12}$ However, in the present review, we focus on formulations where thermosensitivity is achieved by the biophysical properties of the membrane-forming phospholipids
A

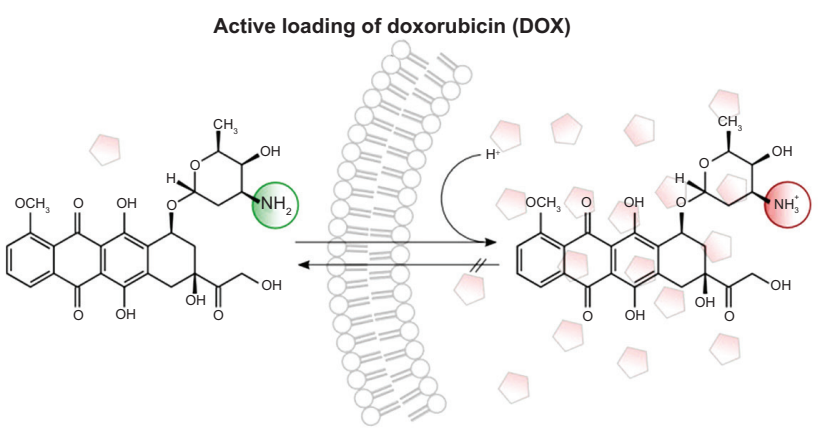

B

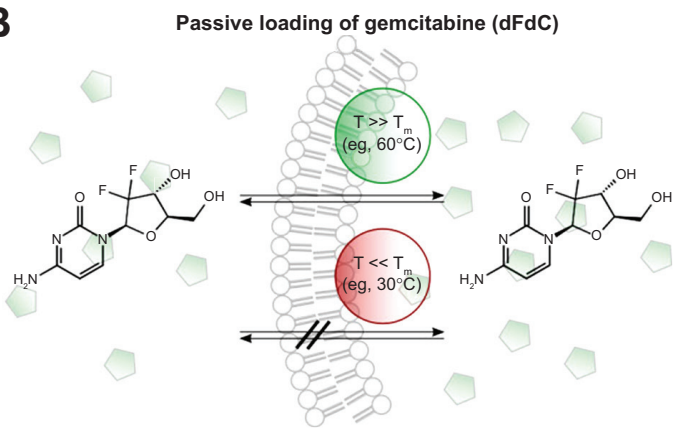

Figure 2 Different methods of drug loading into pre-formed liposomes.

Notes: (A) Active drug loading of weak base molecules (eg, doxorubicin) into preformed liposomes with a pH gradient. In the basic extraliposomal buffer, the drug is uncharged and able to transfer across the membrane bilayer. Inside, the drug is protonated due to the acidic buffer and trapped. The loading method reaches an encapsulation efficacy of up to $98 \%$. (B) Passive drug loading (eg, gemcitabine) is achieved by incubating the drug and vesicles at temperatures where the membrane is in the liquiddisordered phase state and therefore permeable for the drug. After cooling, the membrane is in the solid gel phase state, and its permeability is negligible. Because the passive loading is an equilibrium process depending on the ratio between intraliposomal and extraliposomal volume, the encapsulation efficacy is low and the formulation has to be purified from the nonencapsulated drug.

Abbreviation: dFdC, gemcitabine; DOX, doxorubicin. 
and highlight the influence of lipid composition on the in vitro and in vivo behavior of the TSL formulations currently under investigation. This is in contrast with previously published reviews, which have concentrated on particular TSL formulations ${ }^{10,13,14}$ or image-guided drug delivery. ${ }^{15,16}$

\section{Novel paradigm of drug targeting: intravascular temperature-triggered drug release by external targeting}

Classical PEGylated long-circulating doxorubicin formulations like Doxil/Caelyx have been designed to exploit the enhanced permeability and retention effect (Figure 3A), ${ }^{17}$ and passively accumulate inside tumor tissue because of the leaky tumor vasculature. Nevertheless, passive drug targeting has failed to achieve increased clinical efficacy in humans when compared with the free drug as a result of several shortcomings. Accumulation depends on the specific structure of the tumor vasculature and might be increased by heating the tumor tissue. ${ }^{18,19}$ However, extravasation of vesicles is the rate-limiting step, and nanoparticles have to circulate for days to accumulate in sufficiently high concentrations ${ }^{17}$ because accumulation in tumor tissue competes with uptake in the liver and spleen, and less than $10 \%$ of the injected dose accumulates in the tumor. ${ }^{20}$ Doxil/Caelyx achieves these required long-circulating properties due to its high stability and ability to escape rapid recognition via the reticuloendothelial system. However, the bioavailability of doxorubicin is low. ${ }^{21}$ Seynhaeve et al demonstrated cellular uptake of Doxil/Caelyx via endocytosis and transfer of the intact vesicles to the lysosomal compartment, which markedly impaired delivery of doxorubicin to the nucleus. ${ }^{22}$

Surface modification of Doxil/Caelyx with the anticancer monoclonal antibody $2 \mathrm{C} 5$ resulted in enhanced vesicle accumulation in mouse tumors. ${ }^{23}$ However, active targeting also requires extravasation of liposomes to reach deep-seated tumor cells and suffers from comparable shortcomings known for vesicles for passive targeting (Figure 3A). In recent years, the feasibility of passive drug targeting via the enhanced

A

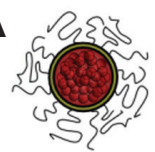
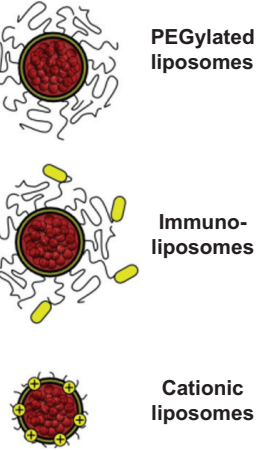

Cationic
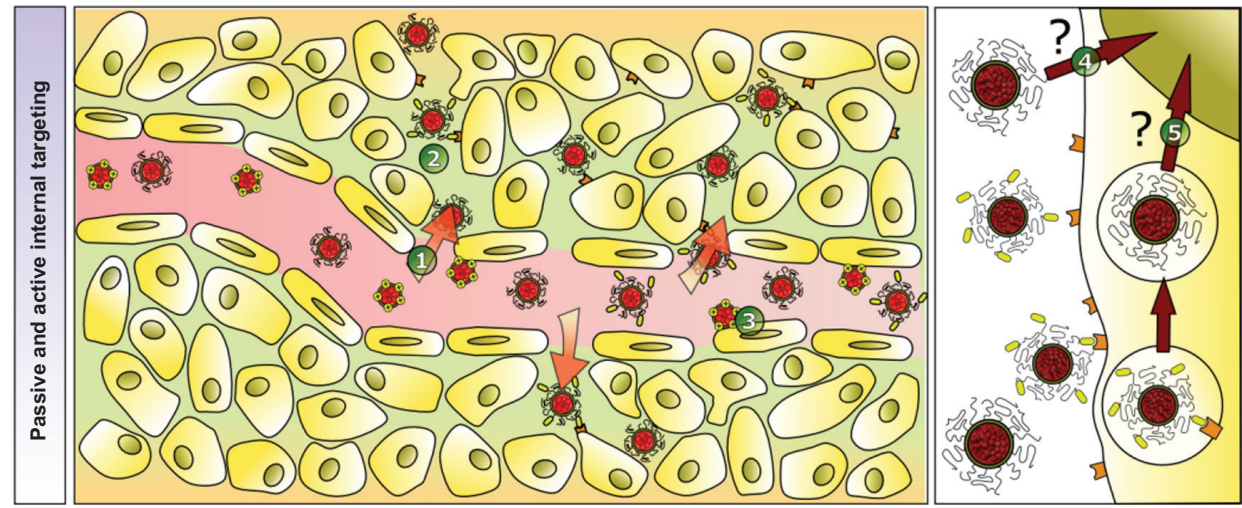

B
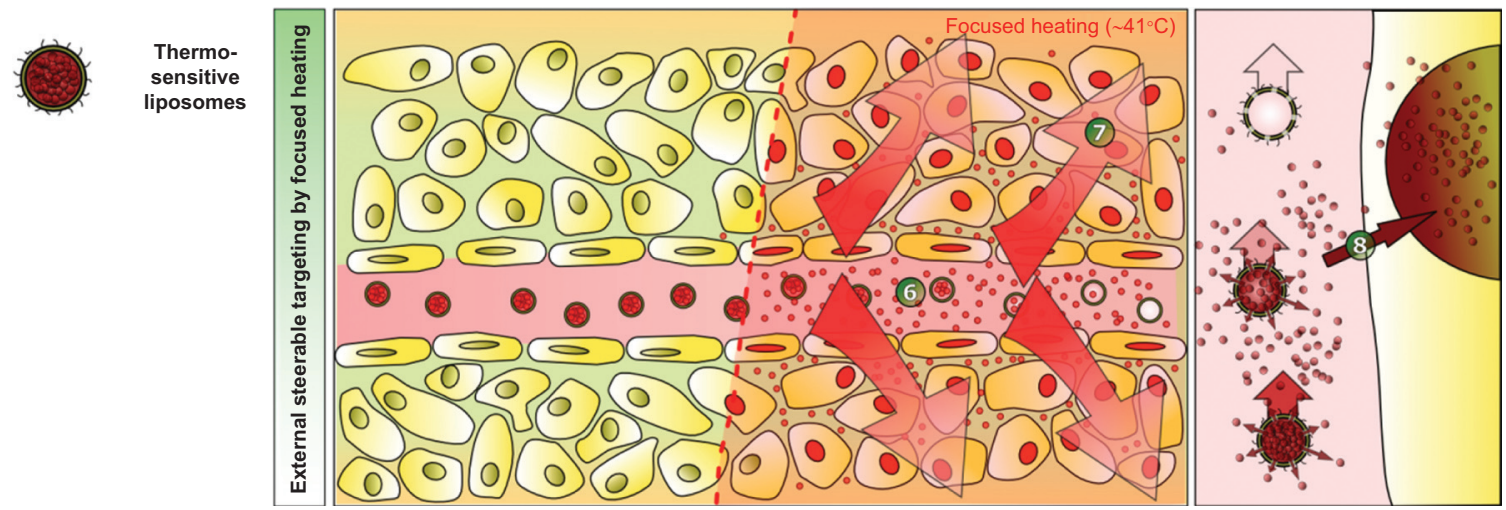

Figure 3 Schematic illustration of targeting concepts with liposomes.

Notes: (A) Passive targeting of drug encapsulated in liposomes is achieved by extravasation of the vesicles into the tumor tissue due to the leaky tumor vasculature (I). This enhanced permeability and retention effect is the rate-limiting step in vesicle accumulation and requires highly stable liposomes with a long circulation half-life in the bloodstream. Even liposomes with targeting moieties attached to their surface (eg, immunoliposomes) have to exploit the enhanced permeability and retention effect to interact with their targets (2). An alternative approach is endothelial targeting with cationic liposomes (3). The drug delivered by stable liposomes is not fully bioavailable and does not reach the tumor cells in sufficient amounts (4). Even after endocytosis of the vesicles, drug delivery is limited, since the drug fails to escape from the endosomal compartment (5) and is subsequently degraded in the lysosome. (B) Intravascular drug release is achievable by thermosensitive liposomes. Release is externally steerable by changing the focus of local heating. After entering the heated tissue, the drug is released into the bloodstream (6), generating a high local drug concentration. The concentration gradient increases the penetration depth of the drug inside tumors (7). The heat-triggered drug release inside the target area overcomes the limitation of traditional targeting concepts, because the drug is fully bioavailable and able to enter its site of action inside the cell (8). 
permeability and retention effect for improving therapeutic efficacy has been controversially discussed. ${ }^{24}$ Another alternative is active targeting of tumor vessels that overexpress negatively charged macromolecules with cationic liposomes (Figure 3A) ${ }^{25}$ However, cationic liposomes are characterized by an increased toxicity profile and rapid clearance from the blood after intravenous application. ${ }^{25}$

A promising alternative, reported by Manzoor et al is external targeting achieved by temperature-triggered, localized intravascular drug release from TSL with focused heating (Figure 3B). ${ }^{26}$ After reaching the heated tumor tissue, doxorubicin was released directly into the bloodstream, generating a high intravascular drug concentration. ${ }^{26,27}$ This led to a significantly increased penetration depth of bioavailable doxorubicin into the tumor tissue when compared with that in animals treated with free doxorubicin or Doxil/Caelyx. ${ }^{26}$ Using this approach, poorly perfused tumor areas, which are known to be more difficult to treat due to a hypoxia-mediated resistance mechanism, could also be reached. The concept of intravascular drug release was then extended to targeting of more hydrophilic drugs, such as gemcitabine. ${ }^{28}$ In contrast with doxorubicin, gemcitabine requires active cellular uptake and enzymatic intracellular activation to gemcitabine triphosphate. Continuous drug release should generate a consistently high intravascular concentration of gemcitabine during application of hyperthermia in the target tissue, reducing the risk of saturation of the gemcitabine-activating enzymes. A clinical pharmacokinetic study demonstrated the superiority of extending gemcitabine exposure by a prolonged infusion time, resulting in increased concentrations of gemcitabine triphosphate inside peripheral blood mononuclear cells. ${ }^{29}$

Additional approaches for temperature-triggered drug delivery have been reported. For long-circulating TSL, it seems reasonable to include a pre-hyperthermia treatment to open up the tumor vasculature for passive accumulation of TSL, ${ }^{18,19}$ followed by a second heat trigger for interstitial drug release. ${ }^{30}$ Such formulations might be further surface-modified for active targeting of the tumor vasculature ${ }^{31,32}$ or tumor cells. ${ }^{33,34}$ For further information about these concepts, the reader is referred to a recent review by Dicheva and Koning. ${ }^{35}$

Temperature-triggered drug targeting by TSL has the advantage of being able to externally control drug release spatially and temporally by steering the heating focus and heating power. Applicators for regional or localized heating of even deep-seated tumor tissue are well established in clinical practice, and are used to heat tumor tissue to temperatures of $42^{\circ} \mathrm{C}$ (mild hyperthermia). ${ }^{36}$ Therefore, commonly used TSL are designed to release the encapsulated drug between $39^{\circ} \mathrm{C}$ and $42^{\circ} \mathrm{C}$. In the following sections, these formulations are summarized and evaluated to their suitability regarding the above-mentioned targeting principles.

\section{Influence of lipid composition on drug release}

Encapsulated hydrophilic drugs are released from TSL at the melting phase transition temperature $\left(\mathrm{T}_{\mathrm{m}}\right)$ of the lipid bilayer. At $\mathrm{T}_{\mathrm{m}}$, the structure of the lipid bilayer changes as transfer from a solid gel phase $\left(\mathrm{L}_{\beta}\right)$ to a liquid-crystalline phase $\left(\mathrm{L}_{\alpha}\right)$ occurs (Figure 4). The membrane is more permeable to water and hydrophilic drugs in the liquid-crystalline phase than when in the gel phase. ${ }^{15,37}$ The permeability of hydrophilic drugs is highest at temperatures around the $T_{m}$ because of the coexistence of membrane areas in both phases forming grain boundaries. ${ }^{38,39}$ DPPC is used as a major component in most TSL formulations because its $\mathrm{T}_{\mathrm{m}}\left(41.4^{\circ} \mathrm{C}\right)$ is above body temperature..$^{40-42}$ Unwanted drug leakage at body temperature can be reduced by mixing DPPC with small amounts of other phospholipids, such as DSPC $\left(\mathrm{T}_{\mathrm{m}}=54.9^{\circ} \mathrm{C}\right) .^{15,42-45}$ The composition of miscible phospholipids determines the $\mathrm{T}_{\mathrm{m}}$ of the formulation (Figure 4B) ${ }^{45,46}$ Basic requirements for TSL are stable drug retention at body temperature in the presence of blood components and a long in vivo half-life, combined with a fast drug release rate around $T_{m}$. Lipid-grafted PEG (eg, 1,2-distearoyl-sn-glycero-3-phosphoethanolamineN-methoxy(PEG)-2000, DSPE-PEG ${ }_{2000}$, Figure 5A) is commonly used in liposomes to create a steric barrier for inhibition of uptake by the reticuloendothelial system and increased blood circulation time, ${ }^{47-49}$ but also potentially affects vesicle stability (Figure 5B). ${ }^{50}$ In addition to phospholipid composition, the manifestation of heat-triggered drug release depends to some degree on the drug molecule encapsulated (Figure 4C), ${ }^{28,51,52}$ vesicle size,${ }^{51}$ and the presence of serum components. ${ }^{45,52}$

\section{In vitro and in vivo behavior of selected formulations}

Until now distinct liposomal formulations have been described, which will be discussed in detail in this section (Table 1).

\section{Traditional temperature-sensitive liposomes}

In 1995, Gaber et al reported the effect of cholesterol and PEG-phosphatidylethanolamine with regard to stabilizing TSL formulations in vitro. ${ }^{45}$ Incorporation of $30 \mathrm{~mol} \%$ cholesterol into TSL formulations eliminated $\mathrm{T}_{\mathrm{m}}$ by changing the phase state of the membrane to a liquid-ordered phase. Vesicles composed of DPPC/HSPC/cholesterol/ 

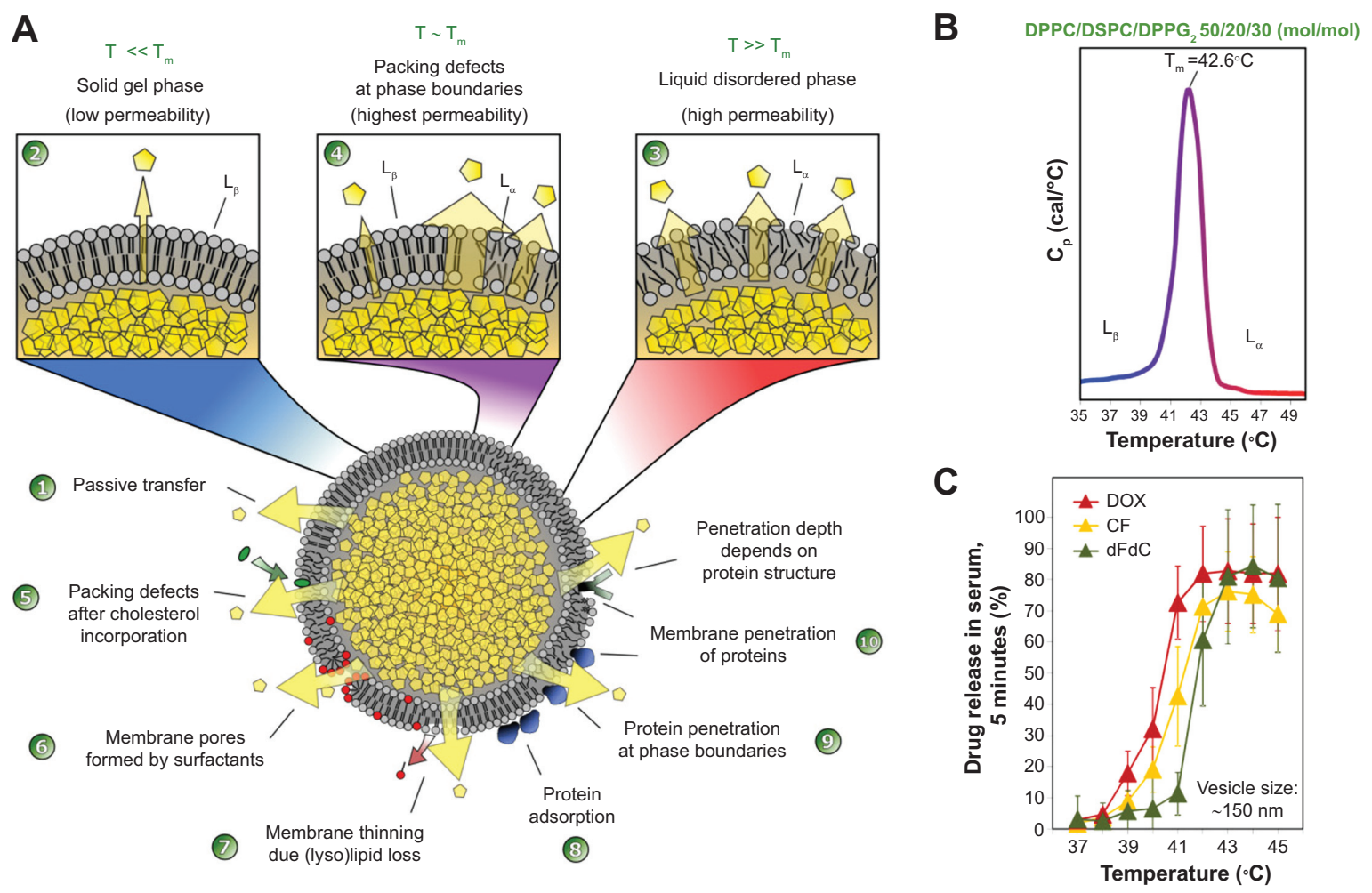

Figure 4 Factors affecting drug release from thermosensitive liposomes.

Notes: $(\mathbf{A})$ The encapsulated drug is released by passive transfer driven by a concentration gradient $(I)$. At body temperature, the phospholipids are in the solid gel $\left(\mathrm{L}_{\beta}\right)$ phase state characterized by low permeability to hydrophilic compounds $(2)$. By increasing the temperature above the phase transition temperature ( $\left.T_{m}\right)$, the phospholipids are in a liquid-crystalline $\left(\mathrm{L}_{\alpha}\right)$ phase state with higher permeability to hydrophilic compounds, because of the higher disorder and movement in the phospholipid packing (3). Around $\mathrm{T}_{\mathrm{m}}$, permeability is the highest because of coexistence of membrane areas in both phases (4). Permeability is further mediated by disturbances in lipid packing induced by lipid incorporation (5), lipid loss (7), and interaction with blood components (8-10). As a specific mechanism of ultrafast drug release from lysolipid-containing TSL, the formation of membrane pores (6) by lysolipids around $T_{m}$ was shown. (B) $T_{m}$ of DPPC/DSPC/DPPG $20: 20: 30$ (mol/mol) (DPPG - TSL) measured by dynamic scanning calorimetry. (C) Temperature-dependent release of hydrophilic compounds from DPPG - TSL measured in fetal calf serum.

Abbreviations: CF, carboxyfluorescein; dFdC, gemcitabine; DOX, doxorubicin; DPPC, I,2-dipalmitoyl-sn-glycero-3-phosphocholine; DSPC, I,2-distearoyl-sn-glycero-3phosphocholine; $\mathrm{DPPG}_{2}$, I,2-dipalmitoyl-sn-glycero-3-phosphodiglycerol; T, temperature; $\mathrm{T}_{\mathrm{m}}$, phase transition temperature; TSL, thermosensitive liposomes.

DPPE-PEG 50:25:15:3 (mol/mol) released $60 \%$ of their doxorubicin content during 30 minutes of incubation at $42^{\circ} \mathrm{C}$ in human plasma. ${ }^{45}$ In vivo fluorescence video microscopy in rats revealed liposome extravasation. ${ }^{53}$ The doxorubicin content in the interstitial space was negligible at $34^{\circ} \mathrm{C}$, but increased by 38 -fold when the tumor was heated to $42^{\circ} \mathrm{C}$ for one hour. ${ }^{53} \mathrm{~A}$ traditional temperature-sensitive liposome (TTSL) formulation with coencapsulated doxorubicin and a gadolinium-based contrast agent for MRI-guided delivery of doxorubicin is currently under investigation. ${ }^{54-57}$ The TTSL formulation has been used in these studies because of its higher stability when compared with lysolipidcontaining low temperature-sensitive liposome (LTSL) formulations. ${ }^{54}$

\section{Lysolipid-containing low temperature-sensitive liposomes}

The breakthrough in development of clinically usable TSL formulations was the incorporation of lysolipids into the membrane bilayer, as described by Needham et al in
2000. ${ }^{11}$ The LTSL formulation was originally composed of DPPC/lyso-PC/DSPE-PEG ${ }_{2000}$ 90:10:4 (mol/mol; Table 1), but was modified slightly in recent years. ${ }^{10}$ The surfactant, lyso-PC (Figure 5A), mediates drug release around $\mathrm{T}_{\mathrm{m}}$ by formation of lysolipid-stabilized membrane pores. ${ }^{10,50,58}$ The release rate of doxorubicin from LTSL at $41.3^{\circ} \mathrm{C}$ was $80 \%$ in 20 seconds. ${ }^{14}$ In comparison, TTSL released only $40 \%$ of its doxorubicin content in 30 minutes on heating to $42^{\circ} \mathrm{C} .{ }^{11,59}$

Complete regression of tumors was achieved in a preclinical xenograft mouse model using doxorubicin encapsulated in LTSL. ${ }^{60}$ In an orthotopic murine mammary model, reduction of blood flow and microvascular density occurred after local application of hyperthermia. ${ }^{61}$ Four xenograft models have been studied, and show that LTSL had improved efficacy in comparison with TTSL. ${ }^{62}$ In 2006, Hauck et al published a Phase I study of LTSL performed in dogs with spontaneously grown solid tumors. ${ }^{63}$ The tumor response achieved supported further evaluation of this formulation, but the maximum tolerated dose of $0.93 \mathrm{mg} / \mathrm{kg}$ was slightly lower than the published dose for free doxorubicin in dogs. ${ }^{63}$ The LTSL 
A

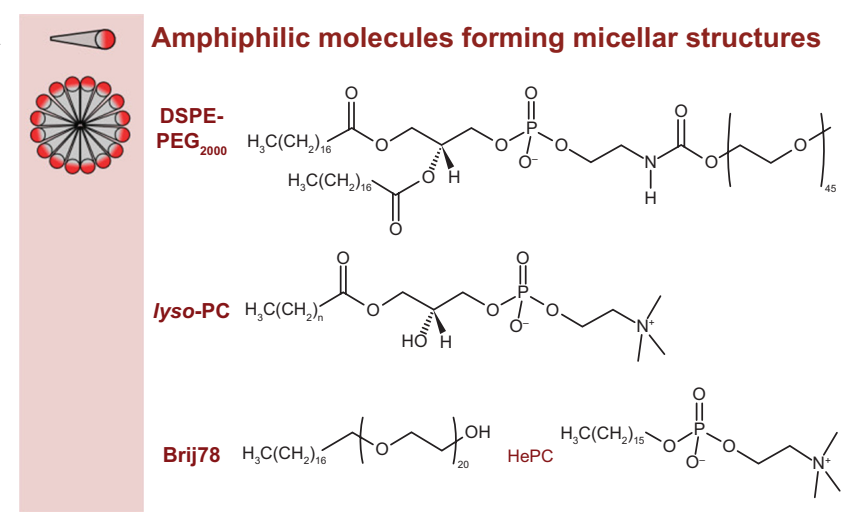

B No surfactants

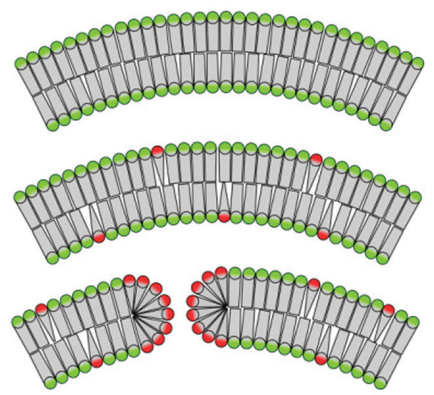

High concentration of surfactants

Figure 5 Micellar-forming amphiphilic molecules as membrane component in liposomes.

Notes: (A) Example of micellar-forming amphiphilic molecules (surfactants) used in liposomal formulations. DSPE-PEG ${ }_{2000}$ is used to increase the circulation half-life of liposomes, and lyso-PC, Brij78, and HePC can be used in thermosensitive formulations to facilitate drug release. (B) Surfactants are incorporated into the membrane bilayers at a low molecular content, but induce formation of usually unwanted structures (eg, membrane pores, dissolution of liposomes) at high concentrations.

Abbreviations: DSPE-PEG 2000 , I,2-distearoyl-sn-glycero-3-phosphoethanolamine-N-methoxy(PEG)-2000; lyso-PC, acyl-sn-glycero-3-phosphocholine; Brij78, polyoxyethylene (20) stearyl ether; HePC, hexadecylphosphocholine.

formulation with encapsulated doxorubicin (Thermodox ${ }^{\circledR}$ ) was licensed to Celsion Corporation (Columbia, MD, USA) and is currently under clinical investigation. ${ }^{10,64}$ Woo et al encapsulated cisplatin into LTSL, but until now only in vitro tests have been published. ${ }^{65}$ Clinical development of the LTSL formulation was recently reviewed in detail, so interested readers are referred to this publication. ${ }^{10}$

LTSL was the first TSL formulation suitable for use in the intravascular drug release approach. This formulation is characterized by ultrafast drug release upon heating, although incorporation of surfactants in the formulation decreases vesicle stability around $\mathrm{T}_{\mathrm{m}} \cdot{ }^{50}$ Moreover, approximately $70 \%$ of lysolipid was found to dissociate from the formulation within one hour post injection. ${ }^{66}$

\section{$\mathrm{DPPG}_{2}$-thermosensitive liposome}

In 2004, a new liposomal formulation ( $\left.\mathrm{DPPG}_{2}-\mathrm{TSL}\right)$ composed of the phospholipids DPPC, DSPC, and

Table I Overview of thermosensitive liposomes

\begin{tabular}{|c|c|c|c|c|c|c|}
\hline Abbreviation & $\begin{array}{l}\text { Membrane } \\
\text { composition }\end{array}$ & $\begin{array}{l}\text { First } \\
\text { publication }\end{array}$ & $\begin{array}{l}T_{m} \\
\text { (encapsulated } \\
\text { doxorubicin) }\end{array}$ & $\begin{array}{l}\text { Encapsulated } \\
\text { drugs }\end{array}$ & $\begin{array}{l}\text { Encapsulated } \\
\text { MRI contrast } \\
\text { agent }\end{array}$ & Targeting principle \\
\hline First TSL & $\begin{array}{l}\text { DPPC/DSPC 3:I } \\
(\mathrm{mol} / \mathrm{mol})\end{array}$ & $1978^{9}$ & - & $\begin{array}{l}\text { Neomycin } 9 \\
\text { Methotrexate }\end{array}$ & - & \\
\hline TTSL & $\begin{array}{l}\text { DPPC/HSPC/Chol/ } \\
\text { DPPE-PEG } \\
\text { 50:25:15:3 }(\mathrm{mol} / \mathrm{mol})\end{array}$ & $1995^{45}$ & $40.9^{\circ} \mathrm{C}^{54}$ & Doxorubicin ${ }^{45,54}$ & Gd-based ${ }^{54}$ & $\begin{array}{l}\text { Passive targeting } \\
\text { before heat-triggered, } \\
\text { interstitial drug release }\end{array}$ \\
\hline LTSL & $\begin{array}{l}\text { DPPC/lyso-PC/DSPE- } \\
\text { PEG }_{2000} \\
90: 10: 4(\mathrm{~mol} / \mathrm{mol})\end{array}$ & $2000^{\prime \prime}$ & $40.8^{\circ} \mathrm{C}^{10}$ & $\begin{array}{l}\text { Doxorubicin"1 } \\
\text { Cisplatinum }\end{array}$ & $\begin{array}{l}\text { Gd-based and } \\
\text { Mn-based }{ }^{5,87-89}\end{array}$ & $\begin{array}{l}\text { Intravascular drug } \\
\text { release }\end{array}$ \\
\hline $\mathrm{DPPG}_{2}-\mathrm{TSL}$ & $\begin{array}{l}\text { DPPC/DSPC/ DPPG } \\
50: 20: 30(\mathrm{~mol} / \mathrm{mol})\end{array}$ & $2004^{67}$ & $41.9^{\circ} \mathrm{C}$ & $\begin{array}{l}\text { Doxorubicin }^{46} \\
\text { Gemcitabine }^{28} \\
\text { Miltefosine }^{71}\end{array}$ & $\begin{array}{l}\text { Gd- and Mn- } \\
\text { based }^{84-86,90,93}\end{array}$ & $\begin{array}{l}\text { Intravascular drug } \\
\text { release }\end{array}$ \\
\hline Stealth TSL & $\begin{array}{l}\text { DPPC/DSPC/ DSPE- } \\
\text { PEG }_{2000} \\
80: 15: 5(\mathrm{~mol} / \mathrm{mol})\end{array}$ & $2007^{46}$ & $43.0^{\circ} \mathrm{C}^{72}$ & Doxorubicin $^{27,72}$ & - & $\begin{array}{l}\text { Passive targeting } \\
\text { before heat-triggered, } \\
\text { interstitial drug release }\end{array}$ \\
\hline HaT & $\begin{array}{l}\text { DPPC/Brij78 96:4 } \\
(\mathrm{mol} / \mathrm{mol})\end{array}$ & $201 I^{73}$ & $41.0^{\circ} \mathrm{C}^{74}$ & $\begin{array}{l}\text { Doxorubicin }^{73} \\
\text { Gemcitabine }^{75} \\
\text { Oxaliplatin }^{75}\end{array}$ & Gd-based ${ }^{97}$ & $\begin{array}{l}\text { Intravascular drug } \\
\text { release }\end{array}$ \\
\hline STL & $\begin{array}{l}\text { DPPC/DSPE-PEG }{ }_{2000} / \\
\text { Chol/ELP 55:2:1 5:0.4I25 } \\
(\mathrm{mol} / \mathrm{mol})\end{array}$ & $2013^{77}$ & - & Doxorubicin ${ }^{77}$ & - & $\begin{array}{l}\text { Intravascular drug } \\
\text { release }\end{array}$ \\
\hline
\end{tabular}

Abbreviations: Brij78, polyoxyethylene (20) stearyl ether; DPPE-PEG, I,2-dipalmitoyl-sn-glycero-3-phosphoethanolamine-N-methoxy(PEG); DPPG, I,2-dipalmitoyl-snglycero-3-phosphodiglycerol; DSPC, I,2-distearoyl-sn-glycero-3-phosphocholine; DSPE-PEG ${ }_{2000}$, I,2-distearoyl-sn-glycero-3-phosphoethanolamine-N-methoxy(PEG)-2000; ELP, fatty acid conjugated elastin-like polypeptide; Gd, gadolinium; HaT, liposome hyperthermia-activated cytotoxic formulation; DPPC, I,2-dipalmitoyl-sn-glycero-3phosphocholine; HSPC, hydrogenated soy phosphatidylcholine; LTSL, lysolipid-containing low-temperature sensitive liposomes; Mn, manganese; MRI, magnetic resonance imaging; TTSL, traditional temperature-sensitive liposome; TSL, thermosensitive liposome; Chol, cholesterol; $T_{m}$, phase transition temperature. 
1,2-dipalmitoyl-sn-glycero-3-phosphodiglycerol ( $\left.\mathrm{DPPG}_{2}\right)$, was reported by Lindner et al. ${ }^{67} \mathrm{DPPG}_{2}$ is a synthetic phospholipid with a molecular weight close to that of natural occurring 1,2-dipalmitoyl-sn-glycero-3-phosphoglycerol, because only one additional glycerol molecule is bound via an ether bond to the head group. ${ }^{67}$ The molecular class of oligoglycerols (Figure 1B, DPPG ${ }_{n}$ ) was developed to increase the circulation half-life of vesicles in the same way as for PEGylated lipids. Lasic et al postulated that highly hydrated groups like PEG on the liposomal surface are capable of sterically inhibiting electrostatic and hydrophobic interactions with blood components. ${ }^{68}$ Incorporation of $\mathrm{DPPG}_{2}$ led to a prolonged circulation time in non-thermosensitive ${ }^{69}$ and thermosensitive ${ }^{28,67}$ formulations. The plasma half-life of carboxyfluorescein encapsulated into $\mathrm{DPPG}_{2}-\mathrm{TSL}$ was reported to be 9.6 hours in hamsters and 5 hours in rats. ${ }^{67}$ Because of the significantly smaller head group modification of the phospholipid compared to DSPE-PEG ${ }_{2000}$ (74 Da versus approximately 2,000 Da), $\mathrm{DPPG}_{\mathrm{n}}$ forms lamellar structures and could be incorporated into TSL formulations with up to $70 \mathrm{~mol} \%{ }^{67}$ Incorporation of DSPE-PEG ${ }_{2000}$ instead is limited to concentrations below $10 \% \mathrm{~mol}$, since it acts like a surfactant with a critical micelle concentration of $0.5-1.0$ $\mu \mathrm{M}^{70} \mathrm{The}_{\mathrm{m}}$ for $\mathrm{DPPG}_{2}-\mathrm{TSL}$ is around $42^{\circ} \mathrm{C}$, with a narrow transition range (Figure 4B).

In contrast with the LTSL formulation, incorporation of surfactants into $\mathrm{DPPG}_{2}-\mathrm{TSL}$ was avoided. However, the release rates of carboxyfluorescein and doxorubicin from $\mathrm{DPPG}_{2}-\mathrm{TSL}$ were as fast as measured with the LTSL formulation, ${ }^{46}$ but drug release from the $\mathrm{DPPG}_{2}-\mathrm{TSL}$ formulation started at approximately one degree higher temperature. ${ }^{46}$ $\mathrm{DPPG}_{2}-\mathrm{TSL}$ showed improved in vitro stability in complete serum when compared with LTSL. ${ }^{52}$ The presence of serum components at $37^{\circ} \mathrm{C}$ stabilized the formulation over time, whereas the opposite was found for LTSL. Interestingly, the lipid composition of a TSL formulation markedly influenced the effect of serum components on vesicle stability. DPPC/ DSPC/DSPE-PEG ${ }_{2000} 80: 15: 5(\mathrm{~mol} / \mathrm{mol})$ (Stealth TSL) and LTSL were more susceptible towards destabilizing effects by cholesterol-containing vesicles, ${ }^{52}$ whereas the presence of immunoglobulin type $\mathrm{G}$ stronger affected the stability of $\mathrm{DPPG}_{2}-\mathrm{TSL}^{52}$ Moreover, the stability of $\mathrm{DPPG}_{2}-\mathrm{TSL}$ was less affected by size changes in the range of 100-150 nm compared to surfactant containing LTSL. ${ }^{51}$

Incorporation of $10 \%$ mol hexadecylphosphocholine (HePC; Figure 5A) into the membrane of $\mathrm{DPPG}_{2}-\mathrm{TSL}$ further increased the release rate of the encapsulated drug, similar to lyso-PC. ${ }^{71} \mathrm{HePC}$ is structurally related to lyso-PC, but has better chemical and metabolic stability, and is approved as a lipophilic drug for the treatment of skin metastasis in breast cancer and for leishmaniasis. The in vitro cytotoxicity of $\mathrm{HePC}$ in $\mathrm{DPPG}_{2}$-TSL was heat-inducible and stronger than that induced by micellar HePC, which did not respond to heat. ${ }^{71}$

Limmer et al passively loaded gemcitabine into $\mathrm{DPPG}_{2}-$ TSL, ${ }^{28}$ and their pharmacokinetic studies in rats using gemcitabine $6 \mathrm{mg} / \mathrm{kg}$ body weight showed an initial plasma half-life of 0.53 hours for gemcitabine encapsulated in $\mathrm{DPPG}_{2}-\mathrm{TSL}$, with a size of $109 \mathrm{~nm}$. The plasma half-life was increased to 2.59 hours when the vesicle size was increased to $129 \mathrm{~nm}$. In a therapeutic study, significant delay of tumor growth was found for heat-triggered gemcitabine from $\mathrm{DPPG}_{2}-\mathrm{TSL}$ when compared with other gemcitabine formulations, including gemcitabine encapsulated in $\mathrm{DPPG}_{2}$-TSL without hyperthermia. ${ }^{28}$

$\mathrm{DPPG}_{2}-\mathrm{TSL}$ is currently the only TSL formulation that fulfills all the criteria for heat-triggered intravascular drug release. Drug release upon activation from this formulation is comparable fast as observed with LTSL formulation. Moreover, the absence of surfactants yields a long-circulating formulation, with high plasma levels after intraveneous application for the duration of a typical hyperthermia treatment in the clinic.

\section{Stealth TSL}

A sterically stabilized TSL formulation (Stealth TSL; Table 1) was developed from the original Yatvin formulation by adding DSPE-PEG ${ }_{2000}$ for improved stability and a better in vivo half-life when compared with the LTSL formulation, ${ }^{46,72}$ and enabled passive accumulation of TSL in tumor tissue. ${ }^{19} \mathrm{Li}$ et al compared Stealth TSL and LTSL, and found that the former had superior in vitro stability at $37^{\circ} \mathrm{C}$ in serum. ${ }^{27}$ The maximum release of doxorubicin from Stealth TSL was at $42^{\circ} \mathrm{C} .{ }^{27}$ In comparison with LTSL, release of doxorubicin from Stealth TSL starts at higher temperatures $\left(39^{\circ} \mathrm{C}\right.$ versus $\left.37^{\circ} \mathrm{C}\right) .{ }^{27}$ Because of the absence of lyso-PC in Stealth TSL, the rate of release of doxorubicin at $42^{\circ} \mathrm{C}$ was slower (75\%, one minute) when compared with LTSL (99\%, one minute). ${ }^{27}$ In a BFS-1 mouse model, Stealth TSL showed improved tumor growth control over LTSL when combined with mild hyperthermia. ${ }^{27}$ Recently, Li et al published a twostep treatment approach. ${ }^{30}$ After prehyperthermia treatment to open up the tumor vasculature, ${ }^{18,19}$ Stealth TSL passively accumulated in the tumor tissue, and a subsequent second hyperthermia treatment allowed interstitial drug release for precise intratumoral drug delivery. ${ }^{30}$ Nevertheless, in tumor growth delay studies, this treatment was less effective than the intravascular temperature-triggered drug release approach, but could be a promising alternative for large and more deep-seated tumors. ${ }^{30}$ 


\section{Hyperthermia-activated cytotoxic formulation}

Another TSL formulation with encapsulated doxorubicin currently under investigation is the hyperthermia-activated cytotoxic (HaT) liposome formulation described by Tagami et al (Table 1). ${ }^{73} \mathrm{HaT}$ is composed of DPPC and the nonionic surfactant, polyoxyethylene (20) stearyl ether (Brij78; Figure 5A). Brij78 consists of a PEGylated acyl chain, so it was hypothesized that Brij78 could replace the function of lyso-PC and DSPE-PEG ${ }_{2000}$ in the LTSL formulation. ${ }^{73,74}$ The HaT formulation showed $100 \%$ doxorubicin release within 3 minutes at a temperature of $40^{\circ} \mathrm{C}-42^{\circ} \mathrm{C}$ in buffer. ${ }^{74} \mathrm{In}$ comparison with LTSL, HaT showed enhanced drug release rates at $40^{\circ} \mathrm{C}$, with similar blood pharmacokinetics. ${ }^{73}$ For both formulations, a blood circulation half-life of approximately 0.5 hours was observed after injection. ${ }^{73}$ A single intravenous treatment with $\mathrm{HaT}$ at a doxorubicin dose of $3 \mathrm{mg} / \mathrm{kg}$ body weight in combination with local hyperthermia showed enhanced tumor regression when compared with LTSL. ${ }^{73}$

Gemcitabine and oxaliplatin have also been encapsulated into the HaT formulation. ${ }^{75}$ In a pharmacokinetic study in mice, $40 \%$ of the injected dose was detectable 2 hours after intravenous administration of gemcitabine encapsulated in HaT. ${ }^{75}$ For oxaliplatin, a three-fold reduction in clearance was observed in comparison with the free drug. ${ }^{75} \mathrm{HaT}$ showed a 25 -fold improvement in delivery of gemcitabine to the heated tumor relative to free gemcitabine. ${ }^{75}$ Unfortunately, superiority of external targeting was not shown in the therapeutic study, because there was no appropriate control group (ie, HaT without hyperthermia).

In 2012, Tagami et al reported an improved method for active loading of doxorubicin into the HaT formulation based on a copper(II) gradient (HaT-II). ${ }^{76}$ HaT-II showed improved in vitro stability at $37^{\circ} \mathrm{C}$, together with a faster drug release rate at $41^{\circ} \mathrm{C}$ in the presence of serum when compared with LTSL. ${ }^{76}$ In comparison with LTSL, HaT-II showed a 2.5fold longer blood circulation time in mice and a 2.0 -fold increase in drug delivery to the heated tumor. ${ }^{76}$ This resulted in improved antitumor efficacy. ${ }^{76}$

\section{STL formulation}

In 2013, Park et al reported another stabilized formulation composed of DPPC, DSPE-PEG ${ }_{2000}$, cholesterol, and fatty acid-conjugated elastin-like polypeptide 55:2:15:0.4125 $(\mathrm{mol} / \mathrm{mol})(\mathrm{STL})$ with encapsulated doxorubicin (Table 1). ${ }^{77}$ Pharmacokinetic studies in mice showed plasma half-lives of 2.03 hours and 0.92 hours for doxorubicin encapsulated in STL and LTSL, ${ }^{77}$ respectively. In combination with high intensity focused ultrasound, STL achieved significantly better tumor growth delay 7 days after injection when compared with LTSL. ${ }^{77}$

\section{Thermosensitive liposomes for MRI-guided drug delivery}

MRI is the method of choice for image-guided drug delivery with TSL. Its abilities with regard to morphological and functional tumor characterization without exposure to ionizing radiation are well known, and it is a standard method in clinical use. Further, MRI thermometry is established for the control of thermotherapies, such as radiofrequency hyperthermia and high intensity focused ultrasound. Dedicated hybrid systems have already been introduced into clinical applications. ${ }^{15,78,79}$ Localized drug release from TSL has been demonstrated in rodents, ${ }^{55,80}$ and nonrodents, ${ }^{81-83}$ using MRI for the control of hyperthermia. Beyond controlling the volume of heating, encapsulation of MRI contrast agents in TSL formulations allows additional characterization of the drug delivery only accessible in humans when using MRI.

\section{Signal mechanism}

Paramagnetic gadolinium chelates ${ }^{5,82,84-86}$ and manganese ions $^{87-90}$ are typical MRI-active contrast agents for encapsulation in TSL formulations (Table 1). The nuclear magnetic resonance of water protons is the primary origin of MRI signal and not the contrast agent itself. MRI contrast agents are only visualized by their ability to accelerate the water proton relaxation in the vicinity of the contrast agent molecules. This indirect signal forming process is only effective if the contrast agent molecule is allowed to interact with a large number of water protons. For visualization of temperature-induced release, the contrast agent has to be encapsulated inside the TSL. ${ }^{91-93}$ Below the $T_{m}$, the contrast agent interacts mainly with the water present inside the TSL, because water exchange with the exterior of the TSL is limited. As a result, the visibility of the contrast agent is reduced when compared with free contrast agents. When approaching the $T_{m}$, the increase in water exchange results in a signal increase in $\mathrm{T}_{1}$-weighted images ${ }^{84}$ Around the $T_{m}$, the contrast agent is released and the signal change is maximal and comparable with the signal change achieved with free contrast agent. ${ }^{84,86,91,92}$ This makes it possible to strongly change an MRI signal by altering temperature. ${ }^{92}$

The maximum achievable signal change depends on the type of contrast agent, ${ }^{86}$ lipid composition, ${ }^{86,91}$ vesicle size, $, 1,91$ and concentration of the encapsulated contrast agent. ${ }^{86,91}$ The heating method might also play a role, eg, focused ultrasound adds a mechanical release component to the signal mechanism. ${ }^{15}$ The signal mechanism described in the paragraph before is mainly related to the contrast agent 
induced change of the longitudinal $\left(\mathrm{T}_{1}\right)$ relaxation time of the water protons. But signal formation in MRI is complex, often showing a weighted signal depending not only on the $\mathrm{T}_{1}$ relaxation time shortening effect but also on the type of pulse sequence, choice of sequence parameters, and effects related to $\mathrm{T}_{2}$ relaxation. Quantification strategies in MRI thus try to determine a single parameter, such as the $T_{1}$ relaxation time, with the aim of being independent of variables such as system settings of an individual measurement or inhomogeneity of the receiver coil. $\mathrm{T}_{1}$ relaxation remains the parameter of choice because it is directly related to the membrane dynamics.

\section{Applications}

TSL can be applied with an encapsulated contrast agent to distinguish heated from unheated tissue $\mathrm{e}^{85,94}$ or to quantify absolute temperatures complementing traditional MRI thermometry methods, ${ }^{95,96}$ thus serving as a tool for quality assurance in thermotherapy in patients.

It has been demonstrated that potentially quantitative estimation of drug release based on $T_{1}$ relaxation time changes is possible if the contrast agent and drug are both encapsulated in a TSL formulation, ${ }^{55,87-89,97}$ thus allowing "drug dose painting" ${ }^{89}$ or "chemodosimetry" ${ }^{88}$ Because the drug itself is not observed by MRI, a correlation between the contrast agent and drug release had to be established. For that purpose, LTSL were actively loaded with doxorubicin using a manganese(II) gradient. ${ }^{87}$ Doxorubicin and manganese(II) form a stable complex, ${ }^{98}$ with the paramagnetic manganese(II) serving as an MRI contrast agent. Thus the release kinetics are the same for the contrast agent and the drug, allowing for correlation between change in $\mathrm{T}_{1}$ relaxation time (determined by MRI) and amount of doxorubicin (determined by high-performance liquid chromatography) ${ }^{88}$ Using this strategy, it was possible to show that release of doxorubicin was heterogeneously distributed in the tumor model, and that LTSL administered during hyperthermia had the greatest antitumor effect when compared with other administration strategies.

The major drawback of the above approach is the toxicity related to manganese(II).

To overcome this, other researchers are using clinically approved gadolinium-based contrast agents. Hossann et al investigated six of these contrast agents for encapsulation in $\mathrm{DPPG}_{2}-\mathrm{TSL}$, and considered a nonionic contrast agent with a low contribution to osmolality to be optimal. ${ }^{86}$ Two strategies of encapsulation are possible using gadoliniumbased contrast agents, but the release kinetics and signal mechanisms for both the contrast agent and drug have to be considered. One strategy is to combine two subsets of TSL, with one encapsulating only the contrast agent and a second encapsulating only the drug. ${ }^{99}$ This strategy allows a higher amount of contrast agent and drug to be encapsulated whilst avoiding osmotic effects. ${ }^{86}$ The second strategy is to coencapsulate both drug and contrast agent in the same TSL, ${ }^{54-57,82,83,97}$ which limits the amount of both components in each TSL. Nevertheless, for both strategies, it has to be ensured that the temperature-dependent drug release rate and MRI signal change are correlated. ${ }^{82}$

An important risk associated with clinical application of a gadolinium-based contrast agent is nephrogenic systemic fibrosis, a rare side effect in patients. The pathophysiological mechanism involves a reduced glomerular filtration rate and a long retention time combined with transmetallation of gadolinium(III). Hijnen et al addressed this concern in a rat model, but could not detect dissociation of gadolinium-DTPA in high intensity focused ultrasound ablation therapy. ${ }^{100} \mathrm{De}$ Smet et al investigated the blood kinetics and biodistribution of ${ }^{111}$ In-labeled TTSL with coencapsulated doxorubicin and gadolinium- $\left(\mathrm{HPDO}_{3} \mathrm{~A}\right)\left(\mathrm{H}_{2} \mathrm{O}\right)$ in Fisher rats, ${ }^{57}$ and found significant clearance with $\leq 0.3 \%$ of the injected dose in all analyzed organs one month after injection. Nevertheless, before application in humans, further investigation of the risks associated with this strategy seems necessary.

\section{Conclusion}

TSL are a promising tool for external targeting of drugs to solid tumors in combination with local hyperthermia or high intensity focused ultrasound. Several formulations have been developed, with one currently under clinical investigation. In vivo results show strong evidence that external targeting is superior over passive targeting of highly stable longcirculating drug formulations. Moreover, MRI-guided drug delivery adds the possibilities of online monitoring of heating focus, calculating locally released drug concentrations, and externally controlling drug release by steering the heating focus and power. The combination of external targeting with TSL and MRI-guided drug delivery will be the unique characteristic of this nanotechnology approach in medicine.

\section{Acknowledgments}

BK was funded by the European Union Seventh Framework Programme (FP7/2007-2013) under grant agreement 603028 (iPaCT project).

\section{Author contributions}

The authors alone were responsible for the content and writing of this paper. 


\section{Disclosure}

The authors report no conflicts of interest in this work.

\section{References}

1. Wagner A, Vorauer-Uhl K. Liposome technology for industrial purposes. J Drug Deliv. 2011;2011:591325.

2. Bangham AD, Standish MM, Watkins JC. Diffusion of univalent ions across the lamellae of swollen phospholipids. J Mol Biol. 1965;13: $238-252$.

3. Gregoriadis G, Wills EJ, Swain CP, Tavill AS. Drug-carrier potential of liposomes in cancer chemotherapy. Lancet. 1974;1:1313-1316.

4. Gregoriadis G. Drug entrapment in liposomes. FEBS Lett. 1973;36: 292-296.

5. Poste G, Bucana C, Raz A, Bugelski P, Kirsh R, Fidler IJ. Analysis of the fate of systemically administered liposomes and implications for their use in drug delivery. Cancer Res. 1982;42:1412-1422.

6. Blume G, Cevc G. Molecular mechanism of the lipid vesicle longevity in vivo. Biochim Biophys Acta. 1993;1146:157-168.

7. Allen TM, Hansen C, Martin F, Redemann C, Yau-Young A. Liposomes containing synthetic lipid derivatives of poly(ethylene glycol) show prolonged circulation half-lives in vivo. Biochim Biophys Acta. 1991;1066:29-36.

8. Wagner V, Dullaart A, Bock AK, Zweck A. The emerging nanomedicine landscape. Nat Biotechnol. 2006;24:1211-1217.

9. Yatvin MB, Weinstein JN, Dennis WH, Blumenthal R. Design of liposomes for enhanced local release of drugs by hyperthermia. Science. 1978;202:1290-1293.

10. Landon CD, Park JY, Needham D, Dewhirst MW. Nanoscale drug delivery and hyperthermia: the materials design and preclinical and clinical testing of low temperature-sensitive liposomes used in combination with mild hyperthermia in the treatment of local cancer. Open Nanomed J. 2011;3:38-64.

11. Needham D, Anyarambhatla G, Kong G, Dewhirst MW. A new temperature-sensitive liposome for use with mild hyperthermia: characterization and testing in a human tumor xenograft model. Cancer Res. 2000;60:1197-1201.

12. van Elk M, Deckers R, Oerlemans C, et al. Triggered release of doxorubicin from temperature-sensitive poly(N-(2-hydroxypropyl)methacrylamide mono/dilactate) grafted liposomes. Biomacromolecules. 2014;15:1002-1009.

13. May JP, Li SD. Hyperthermia-induced drug targeting. Expert Opin Drug Deliv. 2013;10:511-527.

14. Ta T, Porter TM. Thermosensitive liposomes for localized delivery and triggered release of chemotherapy. $J$ Control Release. 2013;169: $112-125$.

15. Grüll H, Langereis S. Hyperthermia-triggered drug delivery from temperature-sensitive liposomes using MRI-guided high intensity focused ultrasound. J Control Release. 2012;161:317-327.

16. Langereis S, Geelen T, Grüll H, Strijkers GJ, Nicolay K. Paramagnetic liposomes for molecular MRI and MRI-guided drug delivery. NMR Biomed. 2013;26:728-744.

17. Maeda $H$. The enhanced permeability and retention (EPR) effect in tumor vasculature: the key role of tumor-selective macromolecular drug targeting. Adv Enzyme Regul. 2001;41:189-207.

18. Kong G, Anyarambhatla G, Petros WP, et al. Efficacy of liposomes and hyperthermia in a human tumor xenograft model: importance of triggered drug release. Cancer Res. 2000;60:6950-6957.

19. Li L, ten Hagen TL, Bolkestein M, et al. Improved intratumoral nanoparticle extravasation and penetration by mild hyperthermia. J Control Release. 2013;167:130-137.

20. Harrington KJ, Mohammadtaghi S, Uster PS, et al. Effective targeting of solid tumors in patients with locally advanced cancers by radiolabeled pegylated liposomes. Clin Cancer Res. 2001;7:243-254.

21. Laginha KM, Verwoert S, Charrois GJ, Allen TM. Determination of doxorubicin levels in whole tumor and tumor nuclei in murine breast cancer tumors. Clin Cancer Res. 2005;11(19 Pt 1):6944-6949.
22. Seynhaeve AL, Dicheva BM, Hoving S, Koning GA, ten Hagen TL. Intact Doxil is taken up intracellularly and released doxorubicin sequesters in the lysosome: evaluated by in vitro/in vivo live cell imaging. J Control Release. 2013;172:330-340.

23. ElBayoumi TA, Torchilin VP. Tumor-targeted nanomedicines: enhanced antitumor efficacy in vivo of doxorubicin-loaded, long-circulating liposomes modified with cancer-specific monoclonal antibody. Clin Cancer Res. 2009;15:1973-1980.

24. Park K. Questions on the role of the EPR effect in tumor targeting. J Control Release. 2013;172:391.

25. Abu Lila AS, Ishida T, Kiwada H. Targeting anticancer drugs to tumor vasculature using cationic liposomes. Pharm Res. 2010;27: 1171-1183.

26. Manzoor AA, Lindner LH, Landon CD, et al. Overcoming limitations in nanoparticle drug delivery: triggered, intravascular release to improve drug penetration into tumors. Cancer Res. 2012;72: $5566-5575$.

27. Li L, ten Hagen TL, Hossann M, et al. Mild hyperthermia triggered doxorubicin release from optimized stealth thermosensitive liposomes improves intratumoral drug delivery and efficacy. J Control Release. 2013;168:142-150.

28. Limmer S, Hahn J, Schmidt R, et al. Gemcitabine treatment of rat soft tissue sarcoma with phosphatidyldiglycerol-based thermosensitive liposomes. Pharm Res. Epub 2014 March 6.

29. Tempero M, Plunkett W, Ruiz Van Haperen V, et al. Randomized phase II comparison of dose-intense gemcitabine: thirty-minute infusion and fixed dose rate infusion in patients with pancreatic adenocarcinoma. J Clin Oncol. 2003;21:3402-3408.

30. Li L, Ten Hagen TL, Haeri A, et al. A novel two-step mild hyperthermia for advanced liposomal chemotherapy. $J$ Control Release. 2014;174: 202-208.

31. Negussie AH, Miller JL, Reddy G, Drake SK, Wood BJ, Dreher MR. Synthesis and in vitro evaluation of cyclic NGR peptide targeted thermally sensitive liposome. J Control Release. 2010;143: 265-273.

32. Dicheva BM, ten Hagen TL, Li L, et al. Cationic thermosensitive liposomes: a novel dual targeted heat-triggered drug delivery approach for endothelial and tumor cells. Nano Lett. 2013;13:2324-2331.

33. Gaber MH. Modulation of doxorubicin resistance in multidrugresistance cells by targeted liposomes combined with hyperthermia. J Biochem Mol Biol Biophys. 2002;6:309-314.

34. Kullberg M, Mann K, Owens JL. A two-component drug delivery system using Her-2-targeting thermosensitive liposomes. J Drug Target. 2009;17:98-107.

35. Dicheva BM, Koning GA. Targeted thermosensitive liposomes: an attractive novel approach for increased drug delivery to solid tumors. Expert Opin Drug Deliv. 2014;11:83-100.

36. Issels RD, Lindner LH, Verweij J, et al. Neo-adjuvant chemotherapy alone or with regional hyperthermia for localised high-risk soft-tissue sarcoma: a randomised phase 3 multicentre study. Lancet Oncol. 2010;11: 561-570.

37. Evans E, Needham D. Physical properties of surfactant bilayermembranes - thermal transitions, elasticity, rigidity, cohesion, and colloidal interactions. J Phys Chem. 1987;91:4219-4228.

38. Mouritsen OG, Zuckermann MJ. Model of interfacial melting. Phys Rev Lett. 1987;58:389-392.

39. Kaasgaard T, Leidy C, Crowe JH, Mouritsen OG, Jorgensen K. Temperature-controlled structure and kinetics of ripple phases in one- and two-component supported lipid bilayers. Biophys J. 2003;85: 350-360.

40. Demel RA, De Kruyff B. The function of sterols in membranes. Biochim Biophys Acta. 1976;457:109-132.

41. Chowdhry BZ, Lipka G, Dalziel AW, Sturtevant JM. Effect of lanthanum ions on the phase-transitions of lecithin bilayers. Biophys $J$. 1984;45:633-635.

42. Mabrey S, Sturtevant JM. Investigation of phase-transitions of lipids and lipid mixtures by high sensitivity differential scanning calorimetry. Proc Natl Acad Sci U S A. 1976;73:3862-3866. 
43. Bassett JB, Anderson RU, Tacker JR. Use of temperature-sensitive liposomes in the selective delivery of methotrexate and cisplatinum analogs to murine bladder-tumor. J Urol. 1986;135:612-615.

44. Maruyama K, Unezaki S, Takahashi N, Iwatsuru M. Enhanced delivery of doxorubicin to tumor by long-circulating thermosensitive liposomes and local hyperthermia. Biochim Biophys Acta. 1993;1149: 209-216.

45. Gaber MH, Hong K, Huang SK, Papahadjopoulos D. Thermosensitive sterically stabilized liposomes: formulation and in vitro studies on mechanism of doxorubicin release by bovine serum and human plasma. Pharm Res. 1995;12:1407-1416.

46. Hossann M, Wiggenhorn M, Schwerdt A, et al. In vitro stability and content release properties of phosphatidylglyceroglycerol containing thermosensitive liposomes. Biochim Biophys Acta. 2007;1768: 2491-2499.

47. Papahadjopoulos D, Gabizon A. Liposomes designed to avoid the reticuloendothelial system. Prog Clin Biol Res. 1990;343:85-93.

48. Allen TM, Hansen CB, Lopes de Menezes DE. Pharmacokineics of long-circulating liposomes. Adv Drug Deliv Rev. 1995;16:267-284.

49. Needham D, McIntosh TJ, Lasic DD. Repulsive interactions and mechanical stability of polymer-grafted lipid membranes. Biochim Biophys Acta. 1992;1108:40-48.

50. Ickenstein LM, Arfvidsson MC, Needham D, Mayer LD, Edwards K Disc formation in cholesterol-free liposomes during phase transition. Biochim Biophys Acta. 2003;1614:135-138.

51. Hossann M, Wang T, Wiggenhorn M, et al. Size of thermosensitive liposomes influences content release. J Control Release. 2010;147: 436-443.

52. Hossann M, Syunyaeva Z, Schmidt R, et al. Proteins and cholesterol lipid vesicles are mediators of drug release from thermosensitive liposomes. J Control Release. 2012;162:400-406.

53. Gaber MH, Wu NZ, Hong K, Huang SK, Dewhirst MW, Papahadjopoulos D. Thermosensitive liposomes: extravasation and release of contents in tumor microvascular networks. Int J Radiat Oncol Biol Phys. 1996;36:1177-1187.

54. de Smet M, Langereis S, van den Bosch S, Grüll H. Temperaturesensitive liposomes for doxorubicin delivery under MRI guidance. J Control Release. 2010;143:120-127.

55. de Smet M, Heijman E, Langereis S, Hijnen NM, Grüll H. Magnetic resonance imaging of high intensity focused ultrasound mediated drug delivery from temperature-sensitive liposomes: an in vivo proof-ofconcept study. J Control Release. 2011;150:102-110.

56. de Smet M, Hijnen NM, Langereis S, et al. Magnetic resonance guided high-intensity focused ultrasound mediated hyperthermia improves the intratumoral distribution of temperature-sensitive liposomal doxorubicin. Invest Radiol. 2013;48:395-405.

57. de Smet M, Langereis S, van den Bosch S, et al. SPECT/CT imaging of temperature-sensitive liposomes for MR-image guided drug delivery with high intensity focused ultrasound. J Control Release. 2013;169:82-90.

58. Mills JK, Needham D. Lysolipid incorporation in dipalmitoylphosphatidylcholine bilayer membranes enhances the ion permeability and drug release rates at the membrane phase transition. Biochim Biophys Acta. 2005;1716:77-96.

59. Gaber MH, Hong KL, Huang SK, Papahadjopoulos D. Thermosensitive sterically stabilized liposomes - formulation and in vitro studies on mechanism of doxorubicin release by bovine serum and human plasma. Pharm Res. 1995;12:1407-1416.

60. Needham D, Dewhirst MW. The development and testing of a new temperature-sensitive drug delivery system for the treatment of solid tumors. Adv Drug Deliv Rev. 2001;53:285-305.

61. Chen Q, Krol A, Wright A, Needham D, Dewhirst MW, Yuan F. Tumor microvascular permeability is a key determinant for antivascular effects of doxorubicin encapsulated in a temperature sensitive liposome. Int $J$ Hyperthermia. 2008;24:475-482.

62. Yarmolenko PS, Zhao YL, Landon C, et al. Comparative effects of thermosensitive doxorubicin-containing liposomes and hyperthermia in human and murine tumours. Int J Hyperthermia. 2010;26:485-498.
63. Hauck ML, LaRue SM, Petros WP, et al. Phase I trial of doxorubicincontaining low temperature sensitive liposomes in spontaneous canine tumors. Clin Cancer Res. 2006;12:4004-4010.

64. Wood BJ, Poon RT, Locklin JK, et al. Phase I study of heat-deployed liposomal doxorubicin during radiofrequency ablation for hepatic malignancies. J Vasc Interv Radiol. 2012;23:248-255.e247.

65. Woo J, Chiu GN, Karlsson G, et al. Use of a passive equilibration methodology to encapsulate cisplatin into preformed thermosensitive liposomes. Int J Pharm. 2008;349:38-46.

66. Banno B, Ickenstein LM, Chiu GN, et al. The functional roles of poly(ethylene glycol)-lipid and lysolipid in the drug retention and release from lysolipid-containing thermosensitive liposomes in vitro and in vivo. J Pharm Sci. 2010;99:2295-2308.

67. Lindner LH, Eichhorn ME, Eibl H, et al. Novel temperature-sensitive liposomes with prolonged circulation time. Clin Cancer Res. 2004;10: 2168-2178.

68. Lasic DD, Martin FJ, Gabizon A, Huang SK, Papahadjopoulos D. Sterically stabilized liposomes: a hypothesis on the molecular origin of the extended circulation times. Biochim Biophys Acta. 1991;1070: 187-192.

69. Schagon O. Liposomen als potentielle Arzneistoffträger: Variation der biopharmazeutischen Eigenschaften durch 1,2-Dipalmitoyl-sn-glycero-oligoglycerine. [Liposomes as drug carriers - variation of biopharmaceutical characteristics by incorporation of 1,2-dipalmitoyl-sn-glycero-3-phosphooligoglycerols]. Aachen, Germany: Shaker Verlag; 1997. German.

70. Ashok B, Arleth L, Hjelm RP, Rubinstein I, Onyuksel H. In vitro characterization of PEGylated phospholipid micelles for improved drug solubilization: effects of PEG chain length and PC incorporation. J Pharm Sci. 2004;93:2476-2487.

71. Lindner LH, Hossann M, Vogeser M, et al. Dual role of hexa decylphosphocholine (miltefosine) in thermosensitive liposomes: active ingredient and mediator of drug release. J Control Release. 2008;125:112-120.

72. Li L, ten Hagen TL, Schipper D, et al. Triggered content release from optimized stealth thermosensitive liposomes using mild hyperthermia. J Control Release. 2010;143:274-279.

73. Tagami T, Ernsting MJ, Li SD. Efficient tumor regression by a single and low dose treatment with a novel and enhanced formulation of thermosensitive liposomal doxorubicin. J Control Release. 2011;152: 303-309.

74. Tagami T, Ernsting MJ, Li SD. Optimization of a novel and improved thermosensitive liposome formulated with DPPC and a Brij surfactant using a robust in vitro system. J Control Release. 2011;154:290-297.

75. May JP, Ernsting MJ, Undzys E, Li S-D. Thermosensitive liposomes for the delivery of gemcitabine and oxaliplatin to tumors. Mol Pharm. 2013;10:4499-4508.

76. Tagami T, May JP, Ernsting MJ, Li SD. A thermosensitive liposome prepared with a $\mathrm{Cu} 2+$ gradient demonstrates improved pharmacokinetics, drug delivery and antitumor efficacy. J Control Release. 2012;161: 142-149.

77. Park SM, Kim MS, Park SJ, et al. Novel temperature-triggered liposome with high stability: formulation, in vitro evaluation, and in vivo study combined with high-intensity focused ultrasound (HIFU). J Control Release. 2013;170:373-379.

78. Peller M, Loffler R, Baur A, et al. [MRI-controlled regional hyperthermia]. Radiologe. 1999;39:756-763. German.

79. Gellermann J, Wlodarczyk W, Hildebrandt B, et al. Noninvasive magnetic resonance thermography of recurrent rectal carcinoma in a 1.5 Tesla hybrid system. Cancer Res. 2005;65:5872-5880.

80. Hijnen NM, Heijman E, Kohler MO, et al. Tumour hyperthermia and ablation in rats using a clinical MR-HIFU system equipped with a dedicated small animal set-up. Int J Hyperthermia. 2012;28:141-155.

81. Staruch R, Chopra R, Hynynen K. Localised drug release using MRIcontrolled focused ultrasound hyperthermia. Int J Hyperthermia. 2011; 27:156-171.

82. Negussie AH, Yarmolenko PS, Partanen A, et al. Formulation and characterisation of magnetic resonance imageable thermally sensitive liposomes for use with magnetic resonance-guided high intensity focused ultrasound. Int J Hyperthermia. 2011;27:140-155. 
83. Ranjan A, Jacobs GC, Woods DL, et al. Image-guided drug delivery with magnetic resonance guided high intensity focused ultrasound and temperature sensitive liposomes in a rabbit Vx2 tumor model. J Control Release. 2012;158:487-494.

84. Wang TT, Hossann M, Reinl HM, et al. In vitro characterization of phosphatidylglyceroglycerol-based thermosensitive liposomes with encapsulated H-1 MR T-1-shortening gadodiamide. Contrast Media Mol Imaging. 2008;3:19-26.

85. Peller M, Schwerdt A, Hossann M, et al. MR characterization of mild hyperthermia-induced gadodiamide release from thermosensitive liposomes in solid tumors. Invest Radiol. 2008;43:877-892.

86. Hossann M, Wang T, Syunyaeva Z, et al. Non-ionic Gd-based MRI contrast agents are optimal for encapsulation into phosphatidyldiglycerol-based thermosensitive liposomes. J Control Release. 2013;166: 22-29.

87. Viglianti BL, Abraham SA, Michelich CR, et al. In vivo monitoring of tissue pharmacokinetics of liposome/drug using MRI: illustration of targeted delivery. Magn Reson Med. 2004;51:1153-1162.

88. Viglianti BL, Ponce AM, Michelich CR, et al. Chemodosimetry of in vivo tumor liposomal drug concentration using MRI. Magn Reson Med. 2006;56:1011-1018.

89. Ponce AM, Viglianti BL, Yu D, et al. Magnetic resonance imaging of temperature-sensitive liposome release: drug dose painting and antitumor effects. J Natl Cancer Inst. 2007;99:53-63.

90. Reinl HM, Hossann M, Lindner LH, Reiser M. Thermosensitive $\mathrm{Mn}^{2+}$ liposomes for MR-guided hyperthermia - solvent-dependent $\mathrm{Mn}^{2+}$ release. IFMBE Proc. 2010;25:21-24.

91. Fossheim SL, Fahlvik AK, Klaveness J, Muller RN. Paramagnetic liposomes as MRI contrast agents: influence of liposomal physicochemical properties on the in vitro relaxivity. Magn Reson Imaging. 1999;17: 83-89.
92. Fossheim SL, Il'yasov KA, Hennig J, Bjornerud A. Thermosensitive paramagnetic liposomes for temperature control during MR imaging-guided hyperthermia: in vitro feasibility studies. Acad Radiol. 2000;7:1107-1115.

93. Reinl HM, Lindner LH, Schneider P, et al. New thermosensitive liposomes for MR-guided hyperthermia. Proc Intl Soc Mag Reson Med. 2003;11:1209.

94. McDannold N, Fossheim SL, Rasmussen H, Martin H, Vykhodtseva N, Hynynen K. Heat-activated liposomal MR contrast agent: initial in vivo results in rabbit liver and kidney. Radiology. 2004;230:743-752.

95. Lindner LH, Reinl HM, Schlemmer M, Stahl R, Peller M. Paramagnetic thermosensitive liposomes for MR-thermometry. Int J Hyperthermia. 2005;21:575-588

96. Hey S, de Smet M, Stehning C, et al. Simultaneous T1 measurements and proton resonance frequency shift based thermometry using variable flip angles. Magn Reson Med. 2012;67:457-463.

97. Tagami T, Foltz WD, Ernsting MJ, et al. MRI monitoring of intratumoral drug delivery and prediction of the therapeutic effect with a multifunctional thermosensitive liposome. Biomaterials. 2011;32: 6570-6578.

98. Chiu GN, Abraham SA, Ickenstein LM, et al. Encapsulation of doxorubicin into thermosensitive liposomes via complexation with the transition metal manganese. J Control Release. 2005;104:271-288.

99. Wang T, Hossann M, Peller M, et al. Dual phosphatidylglyceroglycerol-based thermosensitive liposomes for MR-guided chemothermotherapy. IFMBE Proc. 2010;25:259-260.

100. Hijnen NM, Elevelt A, Grüll H. Stability and trapping of magnetic resonance imaging contrast agents during high-intensity focused ultrasound ablation therapy. Invest Radiol. 2013;48:517-524.
International Journal of Nanomedicine

\section{Publish your work in this journal}

The International Journal of Nanomedicine is an international, peerreviewed journal focusing on the application of nanotechnology in diagnostics, therapeutics, and drug delivery systems throughout the biomedical field. This journal is indexed on PubMed Central, MedLine, CAS, SciSearch ${ }^{\circledR}$, Current Contents ${ }^{\circledR} /$ Clinical Medicine,

\section{Dovepress}

Journal Citation Reports/Science Edition, EMBase, Scopus and the Elsevier Bibliographic databases. The manuscript management system is completely online and includes a very quick and fair peer-review system, which is all easy to use. Visit http://www.dovepress.com/ testimonials.php to read real quotes from published authors. 